Article

\title{
Microstructure and Wear Behavior of TiC/AISI 1020 Metal Matrix Composites Produced by Liquid Pressing Infiltration
}

\author{
Heejeong Kim ${ }^{1}$, Jungyu Park ${ }^{1}$, Sangmin Shin ${ }^{2}$, Seungchan Cho ${ }^{2} \oplus$, Junghwan Kim ${ }^{2}$, Dong-Su Bae ${ }^{1}$ \\ and Ilguk Jo ${ }^{1, *}$ \\ 1 Department of Advanced Materials Engineering, Dong-Eui University, Busan 47340, Korea; \\ heather729@naver.com (H.K.); hsbs511@naver.com (J.P.); dsbae@deu.ac.kr (D.-S.B.) \\ 2 Department of Functional Composites, Korea Institute of Materials Science (KIMS), Changwon 51508, Korea; \\ p996305s@kims.re.kr (S.S.); sccho@kims.re.kr (S.C.); jhwankim@kims.re.kr (J.K.) \\ * Correspondence: ijo@deu.ac.kr
}

check for

updates

Citation: Kim, H.; Park, J.; Shin, S.; Cho, S.; Kim, J.; Bae, D.-S.; Jo, I.

Microstructure and Wear Behavior of TiC/AISI 1020 Metal Matrix Composites Produced by Liquid Pressing Infiltration. Appl. Sci. 2021, 11,9682. https://doi.org/10.3390/ app11209682

Academic Editor: Ion Sandu

Received: 19 September 2021

Accepted: 13 October 2021

Published: 17 October 2021

Publisher's Note: MDPI stays neutral with regard to jurisdictional claims in published maps and institutional affiliations.

Copyright: (c) 2021 by the authors. Licensee MDPI, Basel, Switzerland. This article is an open access article distributed under the terms and conditions of the Creative Commons Attribution (CC BY) license (https:/ / creativecommons.org/licenses/by/ $4.0 /)$.

\begin{abstract}
A metal matrix composite was developed through a unique liquid pressing infiltration process to study the wear mechanism of a TiC reinforced AISI 1020 steel matrix. The microstructure, hardness, and wear behaviors of the TiC/AISI 1020 composite were compared with commercial AISI 52100 bearing steel. Microstructural analysis showed that there were no defects, such as pores or agglomeration of reinforcement particles, and about $60 \%$ of the volume of $\mathrm{TiC}$ was uniformly dispersed. In the case of the AISI 52100 alloy, the hardness was $62.42 \mathrm{HRC}$, which was similar to the 62.84 HRC value of the as-cast TiC/AISI 1020 composite. After the quenching heat treatment, the Rockwell hardness of the composite increased to $76.64 \mathrm{HRC}$, which was attributed to the martensitic transformation of the AISI 1020 matrix. As a result of the pin-on-disc wear test with high contact pressure, the wear width of AISI 52100 was $2937 \mu \mathrm{m}$, which was approximately 4.3 times wider than that of the heat-treated metal matrix composite $(682 \mu \mathrm{m})$. The wear depths of AISI 52100 and the heat-treated composite were $2.6 \mu \mathrm{m}$ and $0.5 \mu \mathrm{m}$, respectively, indicating that TiC/AISI 1020 exhibited excellent wear resistance compared with bearing steel. Improved wear resistance of the TiC/AISI 1020 composite originates from uniformly distributed $\mathrm{TiC}$, with an increase in the hardness due to the heat treatment.
\end{abstract}

Keywords: metal matrix composites; liquid pressing infiltration; microstructure; hardness; wear behavior

\section{Introduction}

AISI 52100 steel is used in various industrial fields due to its excellent machinability, dimensional stability, mechanical properties, and wear resistance, and is widely used as a bearing material [1,2]. However, friction contact under high load pressure conditions and adhesion damages on the surface produce defects, such as white etching cracks, white structure flaking, or decomposition of primary cementite when severe wear occurs $[3,4]$. When such damage occurs, the life of the bearing parts is greatly reduced, which in turn can cause other parts of the machine to degrade, resulting in a total system failure $[5,6]$.

In order to overcome these issues, the development of metal matrix composites in which high hardness ceramic particles are added to a steel matrix to achieve excellent wear resistance have received attention [7]. Metal matrix composites containing ceramic particles have low density and excellent specific strength and specific stiffness, so their application is increasing in automobile and machine parts [8]. Ceramic reinforcements such as boride, nitride, and carbide have excellent wear resistance. As a result, they are widely used as a reinforcing material in metal matrix composites [9]. Among these reinforcements, titanium carbide (TiC) particles are useful because of their low density, thermal stability, high hardness, and high resistance to oxidation and wear [10]. 
Recent metal matrix composite manufacturing methods include powder metallurgy, selective laser melting, and injection molding. When metal matrix composites are manufactured by powder metallurgy, internal defects, such as residual pores and inclusions, may exist, and interfacial defects are generated due to weak wettability between the matrix and the reinforcement [11-13]. Selective laser melting, on the other hand, generally incurs residual stresses due to very high temperature gradients and extreme cooling rates, which can degrade mechanical performance [14,15]. Other work has found that the mechanical and wear properties of ceramic particle-reinforced steel composites made using powder injection molding could degrade the density and mechanical behavior of the composite [16]. In order to overcome the disadvantages of these methods, a liquid phase-based liquid pressing infiltration method was developed, which has an excellent wettability of ceramic reinforcement and is known to exhibit effective load transfer due to excellent bonding strength [17].

In this study, a TiC/AISI 1020 composite was prepared by the liquid pressing infiltration method, and the microstructure, hardness, and wear resistance were studied. The wear behavior and mechanism of the AISI 52100 steel and the TiC/AISI 1020 composite wwere investigated via pin-on-disc tests.

\section{Materials and Methods}

\subsection{Materials and Liquid Pressing Infiltration Process}

In this study, the microstructure, hardness, and wear behaviors of a TiC-reinforced AISI 1020 composite, which was manufactured by liquid pressing infiltration, were investigated. In order to produce a $\mathrm{TiC}$ preform for the infiltration, $\mathrm{TiC}$ powder (Changsha Langfeng Metal Materials Co., Ltd.) with an average particle size of $3 \mu \mathrm{m}$ was uniaxially pressured in a steel die at $80 \mathrm{MPa}$. The TiC preform (diameter $100 \mathrm{~mm}$; height $50 \mathrm{~mm}$ ) was then sintered for $2 \mathrm{~h}$ in an argon atmosphere at $1400^{\circ} \mathrm{C}$. The volume fraction of the $\mathrm{TiC}$ reinforcement in the preform was about $60 \%$. Figure 1 shows SEM micrographs of raw and sintered TiC preform. The formation of necks was perceived in the preform after sintering without change in the $\mathrm{TiC}$ morphology.
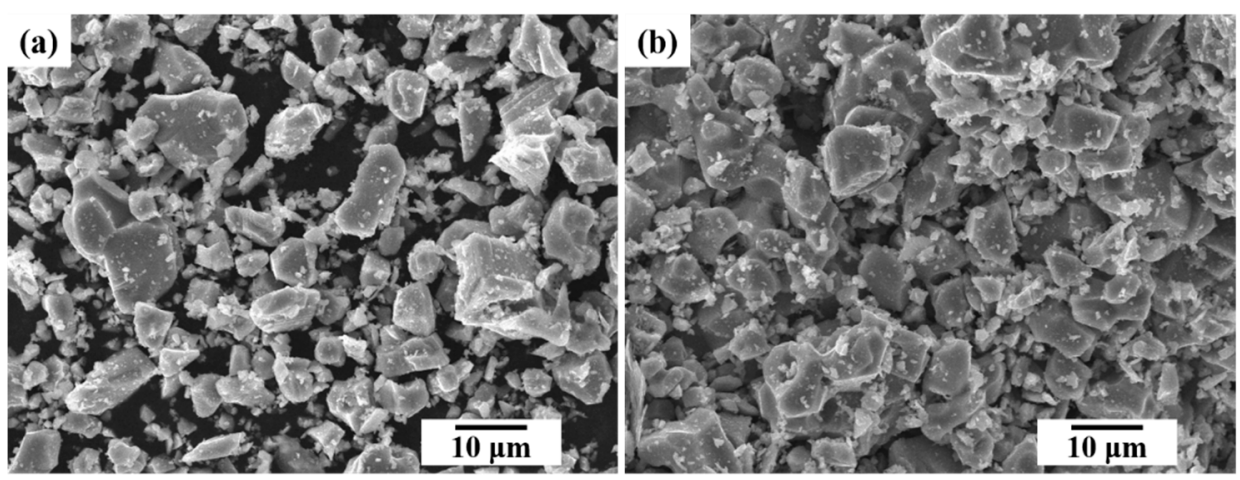

Figure 1. SEM micrograph of (a) raw TiC powder and (b) sintered TiC preform.

After the TiC preform preparation, a TiC/AISI 1020 composite was manufactured using the liquid pressing infiltration method [17]. The AISI 1020 was melted under a vacuum of $10^{-2}$ Torr in a chamber. The molten AISI 1020 alloy was infiltrated into the TiC preform at $1600{ }^{\circ} \mathrm{C}$ and then pressurized with an argon pressure of $10 \mathrm{bar}$ for $20 \mathrm{~min}$. The processing conditions were derived through simulation under conditions in which molten metal could sufficiently infiltrate into the reinforcement preform. After the pressurization, the composites were cooled in the furnace. Through this process, the TiC/AISI 1020 composite with a rectangular shape of $100 \times 50 \mathrm{~mm}$ was prepared. 


\subsection{Characterization}

The microstructure and wear properties of the most commonly used bearing material (induction-hardened AISI 52100 alloy [high chromium steel]) were taken for comparison with the composite. The composition of AISI 52100 bearing steel and AISI 1020 steel for the composite matrix is shown in Table 1.

Table 1. Composition of AISI 52100 and AISI 1020 alloy.

\begin{tabular}{ccccccccccc}
\hline Elements & $\mathbf{C}$ & $\mathbf{S i}$ & $\mathbf{M n}$ & $\mathbf{P}$ & $\mathbf{S}$ & $\mathbf{C u}$ & $\mathbf{N i}$ & $\mathbf{C r}$ & $\mathbf{M o}$ & $\mathbf{F e}$ \\
\hline \multirow{2}{*}{ AISI 52100 wt. \% } & 0.95 & 1.5 & 0.5 & 0.25 & 0.25 & 0.25 & 0.25 & $1.3 \sim 1.6$ & 0.08 & Bal. \\
& $\sim 1.1$ & $\sim 3.5$ & & & & & & & \\
AISI 1020 wt. \% & 0.18 & 0.15 & 0.3 & 0.03 & 0.035 & 0.3 & 0.2 & 0.2 & & Bal. \\
& $\sim 0.23$ & $\sim 0.35$ & $\sim 0.6$ & max. & max. & max. & max. & max. & & \\
\hline
\end{tabular}

The TiC/AISI 1020 metal matrix composite manufactured by liquid pressing infiltration was kept at $890^{\circ} \mathrm{C}$ for $1 \mathrm{~h}$ and then heat treated with quenching to improve the mechanical properties. This is a heat treatment condition that can cause sufficient martensitic transformation of AISI 1020 steel. For AISI 52100 and TiC/AISI 1020, the samples were cross sectioned and prepared using standard metallographic procedures. First, the specimens were abraded on $\mathrm{SiC}$ paper to 2400 grits and then polished down to $1 \mu \mathrm{m}$ using a diamond paste. ImageJ software version $1.52 \mathrm{a}$ was used to calculate the $\mathrm{TiC}$ volume fraction of the produced composite. For the phase analysis of the AISI 52100 material and the TiC/AISI 1020 composite, X-ray diffraction (XRD; D/Max-2500, Rigaku) with $\mathrm{Cu} \mathrm{K}_{\text {_ radiation }}(\mathrm{k}=0.15406 \mathrm{~nm})$ operated at $40 \mathrm{kV}$ and $100 \mathrm{~mA}$, and the microstructure was analyzed using an optical microscope and a scanning electron microscope (SEM; JSM-6610LV, JEOL). The hardness of the manufactured metal matrix composite wear test specimen before and after heat treatment, the AISI 52100 wear test specimen, and the H13 counterpart pin was measured five times by using a Rockwell hardness tester (HR-210MR, Mitutoyo), and the average value was calculated. In order to analyze the wear behavior of the AISI 52100 bearing steel and the metal matrix composite manufactured by the liquid pressure infiltration method, pin-on-disc sliding wear tests with similar motion to the movement of the bearing parts were conducted. For the wear tests, AISI 52100 and the $\mathrm{TiC} / \mathrm{AISI} 1020$ composite were machined into a disc shape, and an $\mathrm{H} 13$ pin $(\Phi 4 \times 8 \mathrm{~mm})$ was used as the counterpart, as shown in Figure 2. The wear tests were carried out with a load of $20 \mathrm{~N}$ at a linear speed of $0.5 \mathrm{~m} / \mathrm{s}$ for $1 \mathrm{~km}$ wear distance in atmospheric conditions. The $\mathrm{H} 13$ pin was polished to 2000 grit, and the disc wear test specimen was polished down to $0.25 \mu \mathrm{m}$. Considering the high contact pressure applied to an actual bearing, 1.6 GPa contact pressure was applied between the disc and the pin. After the wear test, the wear surface was analyzed using the SEM, and the wear depth and width were measured using the surface roughness measuring method (Alpha Step).
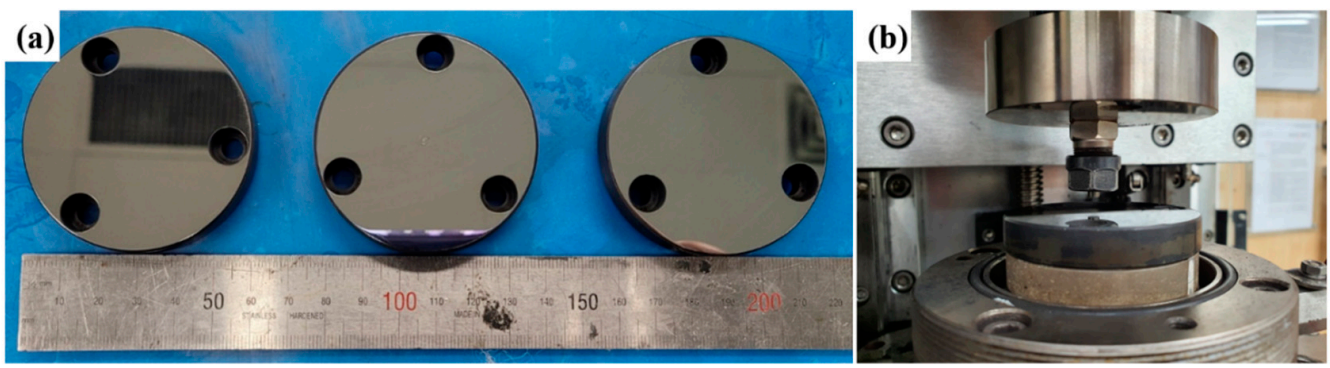

Figure 2. (a) Wear test specimens (AISI 52100, TiC/AISI 1020) and (b) pin-on-disc sliding wear tester. 


\section{Results and Discussion}

\subsection{Crystal and Microstructure}

Figure 3 shows the results of the crystal structure and microstructural analysis of induction-hardened AISI 52100 bearing steel. It was confirmed that some retained austenite with a face-centered cubic structure and a black-colored phase spherical in shape were finely distributed in the martensitic matrix. As a result of the SEM microscopy and compositional analysis of the AISI 52100 steel (Figure 3c), it was observed that black, round-shaped carbides with a diameter of about $1 \mu \mathrm{m}$ were uniformly distributed in the matrix as a (Fe. $\mathrm{Cr})_{3} \mathrm{C}$ phase, as confirmed by XRD and optical microscopy. It is known that these carbides in AISI 52100 bearing steel improve wear resistance and corrosion resistance.
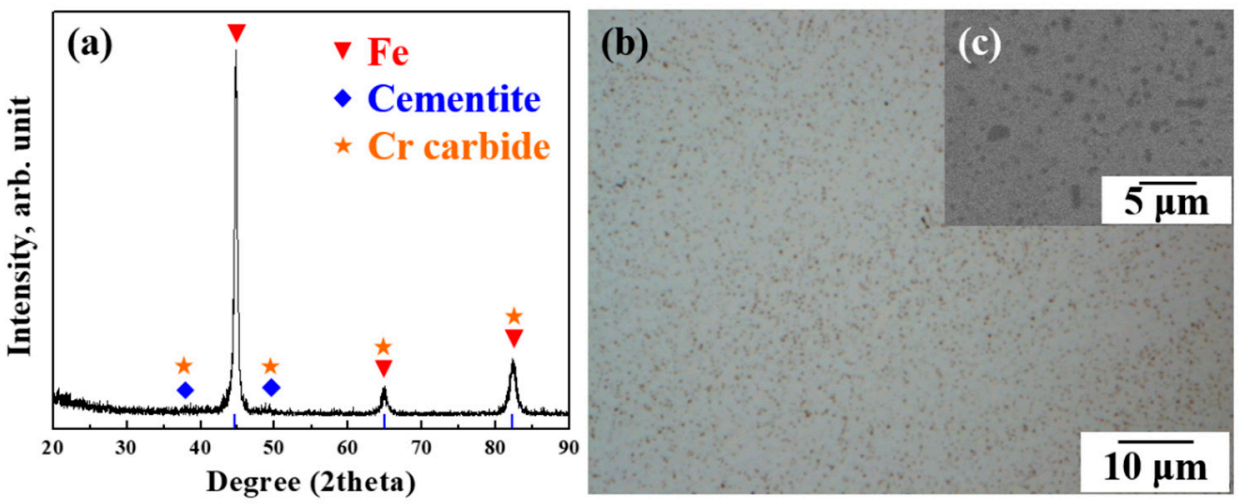

Figure 3. (a) XRD, (b) OM, and (c) SEM analysis results of AISI 52100 bearing steel.

Figure 4 shows the results of $\mathrm{XRD}$ analysis before and after quenching heat treatment on the TiC-reinforced AISI 1020 matrix composite. Before the quenching heat treatment, the $\alpha$-Fe (ferrite) matrix and the TiC phase were confirmed, and a second phase, such as including other impurities or unwanted chemical reactants, was not observed. The composite specimen was maintained at $890^{\circ} \mathrm{C}$ for $1 \mathrm{~h}$ and then water quenched, and had two main phases. After quenching heat treatment, a broadening of the $\alpha$-Fe peak was observed, which is attributed to the martensitic (BCT lattice structure) phase transformation during the quenching heat treatment, resulting in a change in lattice spacing and residual stress. The inducement of dislocation formation may have occurred due to the difference in thermal expansion coefficients between the matrix and the reinforcement.

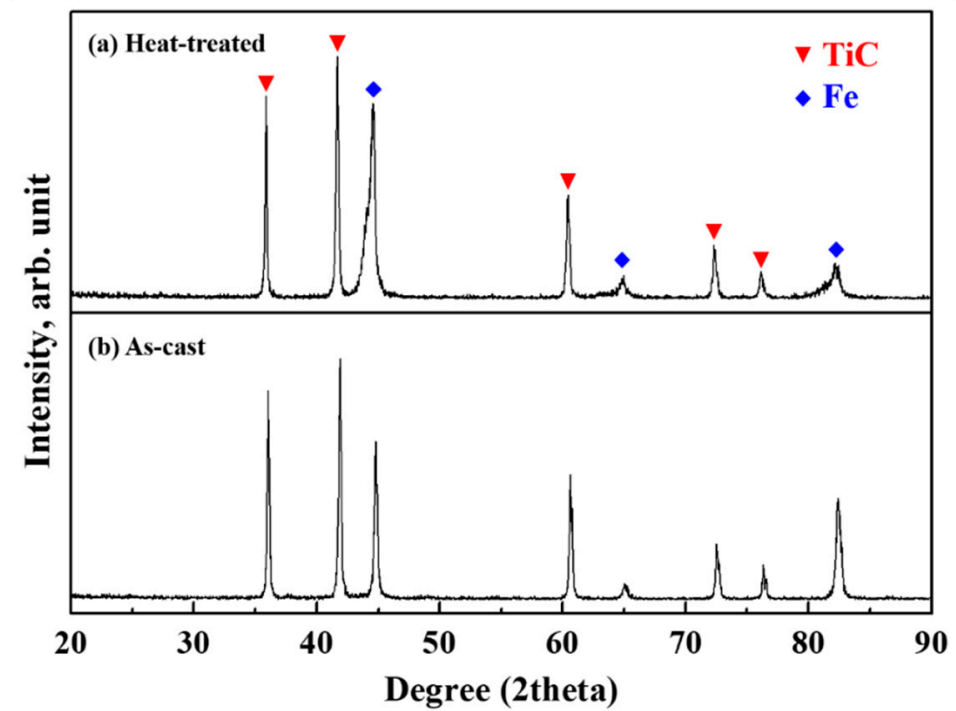

Figure 4. XRD analysis of (a) heat-treated TiC/AISI 1020 composite and (b) as-cast TiC/AISI 1020. 
Figure 5 shows the microstructural observation results of the TiC/AISI 1020 matrix composite using an SEM. As can be seen from Figure 5, it was confirmed that spherical TiC particles with a size of $1-5 \mu \mathrm{m}$ were uniformly distributed in the AISI 1020 alloy matrix. From the XRD analysis and the microstructural analysis results, a metal matrix composite with uniform distribution of TiC reinforcement in AISI 1020 was successfully manufactured by liquid pressing infiltration without impurities or unwanted phases. The TiC volume fraction in the TiC/AISI 1020 composite calculated through image analysis was about $60 \%$, which matched the $\mathrm{TiC}$ volume fraction to the $\mathrm{TiC}$ preform before infiltration.
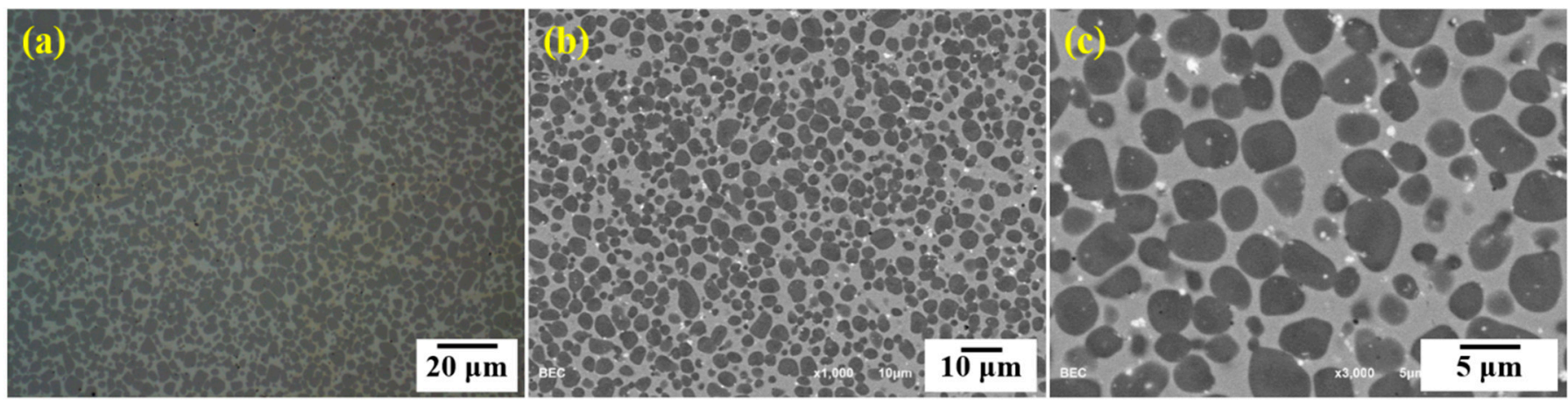

Figure 5. SEM micrographs of TiC/AISI 1020 composite with different magnifications: (a) $500 \times$, (b) $1000 \times$, and (c) $3000 \times$.

\subsection{Wear Behavior}

Table 2 shows the Rockwell C scale hardness values of the AISI 52100 bearing steel, TiC/AISI 1020 composite, and H13 counterpart pin. In the case of AISI 52100, the average Rockwell hardness value is $62.42 \mathrm{HRC}$, which is similar to the $62.84 \mathrm{HRC}$ value of the $\mathrm{TiC} / \mathrm{AISI} 1020$ composite before heat treatment. After heat treatment, the hardness of the metal matrix composite is $76.64 \mathrm{HRC}$, which is an increase of more than $20 \%$ compared to before heat treatment. This is attributed to the martensitic transformation of the AISI 1020 matrix by heat treatment, as confirmed by XRD and microstructure analyses. The hardness value of the $\mathrm{H} 13$ counterpart pin was $58.08 \mathrm{HRC}$.

Table 2. Rockwell C hardness of AISI 52100, TiC/AISI 1020, and H13 pin.

\begin{tabular}{ccccc}
\hline HRC & AISI 52100 & $\begin{array}{c}\text { TiC/AISI 1020 } \\
\text { (As-Cast) }\end{array}$ & $\begin{array}{c}\text { TiC/AISI 1020 } \\
\text { (Heat-Treated) }\end{array}$ & Pin (H13) \\
\hline$\# 1$ & 62.6 & 62.5 & 76.4 & 57.0 \\
$\# 2$ & 62.5 & 61.8 & 76.9 & 58.7 \\
$\# 3$ & 62.3 & 63.9 & 76.6 & 58.4 \\
$\# 4$ & 62.5 & 62.8 & 76.7 & 58.2 \\
$\# 5$ & 62.2 & 63.2 & 76.6 & 58.1 \\
Average & 62.42 & 62.84 & 76.64 & 58.08 \\
\hline
\end{tabular}

Figure 6 shows the wear surface after the wear test of AISI 52100, in which brightcolored particles marked with yellow dotted circles were observed in several places on the wear tracks. Following observation at high magnification, black adhesive wear was also seen, as indicated by the yellow arrows. Table 3 shows the results of EDS compositional analysis in the area indicated by the yellow circles and arrows in Figure 6. Elements such as $\mathrm{C}, \mathrm{O}, \mathrm{Al}, \mathrm{Fe}$, and $\mathrm{Si}$ were mainly detected in the yellow circles in Figure 6, and it was judged that oxides were generated by the aggregation of various alloying elements during the wear test. The yellow arrows in Figure $6 \mathrm{c}$ indicate that $\mathrm{O}$ and Fe elements were mainly detected, and these reacted with the ambient atmosphere at the contact surface to generate oxides on the surface. From the experimental data, the wear mechanism of AISI 52100 steel during the pin-on-disc sliding wear test was deduced as follows: step 1: elastic and plastic deformation of AISI 52100, step 2: adhesion of the deformed part, step 3: wear progress by 
the shearing of the adhesion part. From the above results, during the wear test, reaction products such as oxides are first generated on the surface of the AISI 52100 material by reacting with the surrounding atmosphere (yellow arrows in Figure 6), and, when they come into contact, shearing occurs and the reaction layer is sheared and delaminated. The broken reaction layer is oxidized again, and, as this phenomenon is repeated, wear fragments stick together, which is thought to generate particles marked with yellow circles.
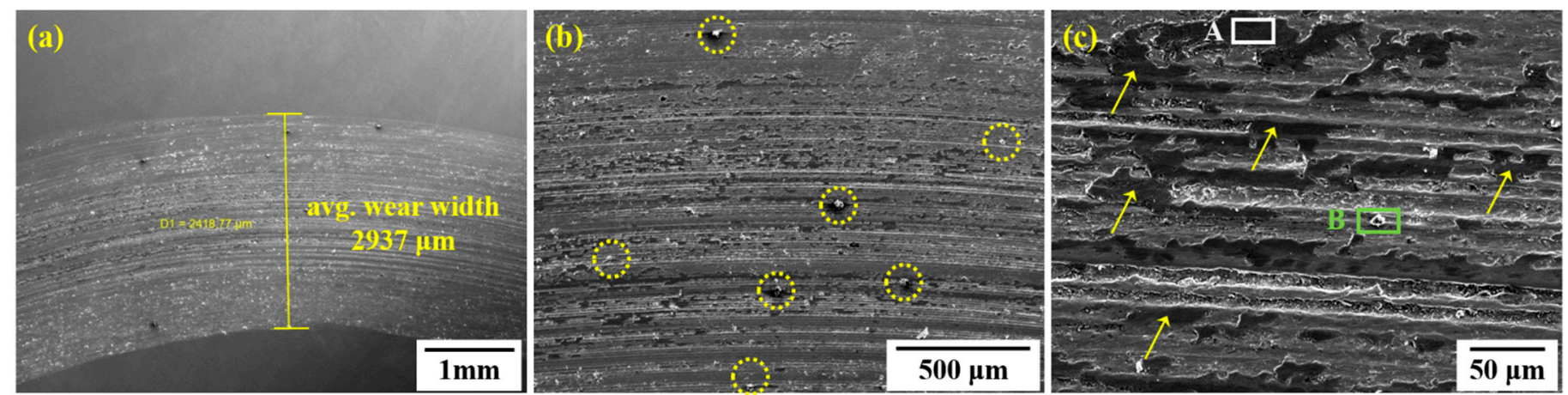

Figure 6. SEM micrographs of AISI 52100 wear surface with magnifications of $(\mathbf{a}) \times 50,(\mathbf{b}) \times 150$, and (c) $\times 1000$ (A,B: EDS analysis area; yellow dotted circles: adhesive wear area; yellow arrows: wear fragments).

Table 3. SEM-EDS compositional analysis of the A and B areas of Figure 5c.

\begin{tabular}{cccccccccc}
\hline At. $\%$ & $\mathbf{C}$ & $\mathbf{O}$ & $\mathbf{M g}$ & $\mathbf{A l}$ & $\mathbf{S i}$ & $\mathbf{M o}$ & $\mathbf{C r}$ & $\mathbf{M n}$ & Fe \\
\hline A & 5.44 & 43.73 & 0 & 0 & 1.01 & 0.31 & 1.97 & 0.65 & 46.88 \\
B & 23.26 & 32.22 & 1.15 & 19.77 & 11.00 & 0 & 0 & 0 & 12.60 \\
\hline
\end{tabular}

Figure 7 shows the wear track of the TiC/AISI 1020 metal matrix composite using an SEM. Compared to the AISI 52100 bearing material, the wear did not proceed much and the wear width was narrow. In addition, TiC reinforcement removed from the metal matrix composite wear surface part was not observed. The part marked with yellow circles was partially observed, and, from the high-magnification images, it was confirmed as a matrixrich area with less reinforcement. Compositional analysis was undertaken for a more detailed investigation. As a result of component analysis, the area of reinforcement not observed was mainly comprised of $\mathrm{O}$ and $\mathrm{Fe}$. As the wear test proceeded, the oxidation of the AISI 1020 matrix-rich part (yellow circles) occurred, and the part with TiC reinforcement remained as the manufactured state without oxidation. These matrix-rich parts occurred during the preform manufacturing process or the liquid pressure infiltration process, but, as a result of this wear phenomenon, it was judged that it does not significantly affect the metal matrix composite overall wear behavior.
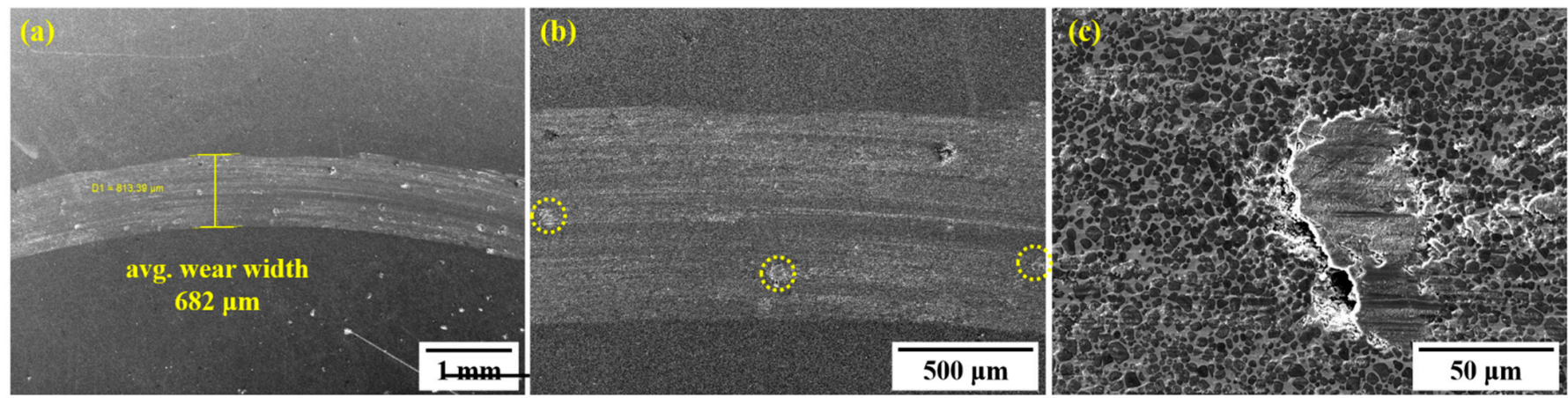

Figure 7. SEM micrographs of TiC/ AISI 1020 wear surface with $(\mathbf{a}) \times 50,(\mathbf{b}) \times 150$, and $(\mathbf{c}) \times 1500$ magnifications (yellow dotted circles: matrix rich area). 
Figure 8 shows the microstructure of the wear surface of the H13 counterpart pin material. As shown in Figure 8, after the wear test of AISI 52100 and TiC/AISI 1020, an adhesive wear on the pin surface was observed. In the case of the H13 pin tested with a metal matrix composite, there was severe adhesive wear. This indicates that TiC/AISI 1020 with high hardness has superior wear resistance than that of the H13 pin. After the wear tests, the pins were compared. The TiC/AISI 1020 metal matrix test pin had more wear than the AISI 52100 sample pin, indicating that the metal matrix material has better wear resistance than the AISI 52100 bearing steel.
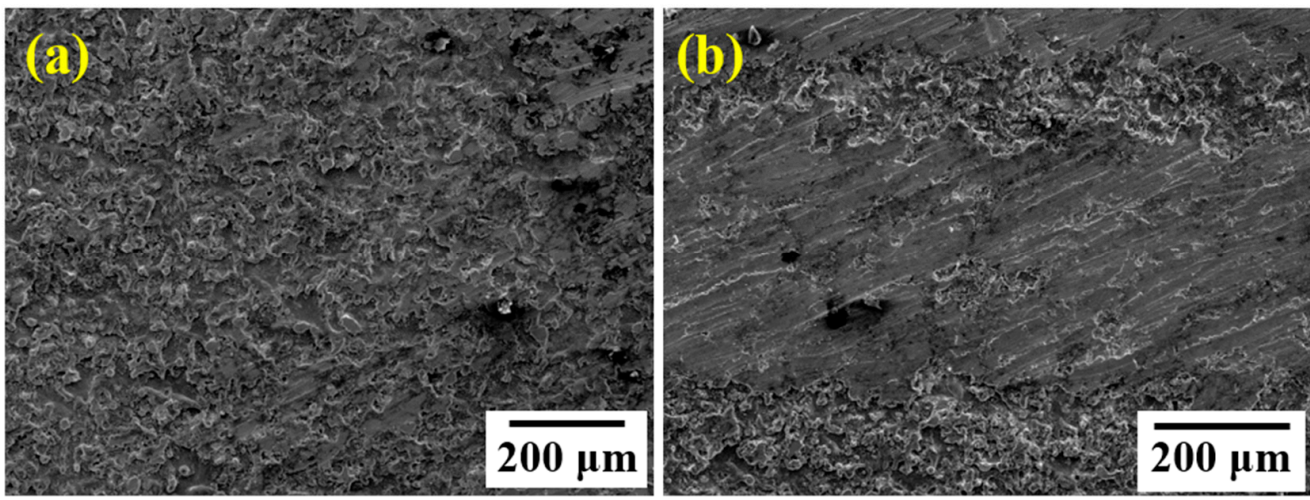

Figure 8. SEM micrographs of pin wear surface against (a) AISI 52100 specimen and (b) TiC/AISI 1020 composite.

Table 4 displays the wear width and wear depth of AISI 52100 and the TiC/AISI 1020 composite after the pin-on-disc tests. In the case of the metal matrix composite, the wear width was $682 \mu \mathrm{m}$, whereas in the case of AISI 52100, the wear width was $2937 \mu \mathrm{m}$. The wear width of AISI 52100 was about three times wider than that of TiC/AISI 1020. The hardness of the heat-treated composite was $76.64 \mathrm{HRC}$, which was much higher than that of AISI 52100 (62.42 HRC), and the higher the hardness yield, the better the wear resistance. The wear depth of the AISI 52100 bearing material and composite was also measured and compared. Profile measurements show that the wear depth of the TiC/AISI 1020 composite $(0.5 \mu \mathrm{m})$ was much smaller than that of the AISI 52100 bearing steel $(3 \mu \mathrm{m})$.

Table 4. Wear width and wear depth of AISI 52100 steel and TiC/ AISI 1020 composite.

\begin{tabular}{ccc}
\hline & AISI 52100 & AISI 1020/TiC \\
\hline Wear width, $\mu \mathrm{m}$ & 2937 & 682 \\
Wear depth, $\mu \mathrm{m}$ & 2.6 & 0.5 \\
\hline
\end{tabular}

\section{Conclusions}

In this study, a TiC / AISI 1020 metal matrix composite was manufactured using a liquid pressing infiltration method, and its properties were compared with AISI 52100 bearing steel. From analyzing the microstructure of the manufactured metal matrix material, it was confirmed that the $\mathrm{TiC}$ reinforcement was uniformly dispersed in the matrix, and there were no defects, such as cracks or pores, or chemical reactants. The average Rockwell hardness value of AISI 52100 was $62.42 \mathrm{HRC}$, and the hardness of the heat-treated composite was 76.64 HRC, which was about 25\% higher than the AISI 52100 steel. From the pin-on-disc wear test, the wear width and depth of TiC/AISI 1020 were $682 \mu \mathrm{m}$ and $0.5 \mu \mathrm{m}$, respectively, which were smaller than those of AISI $52100(2937 \mu \mathrm{m}$ and $2.6 \mu \mathrm{m})$. In the case of the TiC/AISI 1020 metal matrix composite manufactured by liquid pressing infiltration, it was confirmed that the high hardness of $\mathrm{TiC}$ particles was uniformly distributed on the AISI 1020 matrix, thereby improving the hardness and wear resistance of the composite as compared with AISI 52100 bearing steel. The composite material with TiC reinforcement 
can endure more severe wear conditions than commercial AISI 52100 bearing material, and the hardness and wear behavior can be improved by a quenching heat treatment.

Author Contributions: Conceptualization, J.K. and I.J.; methodology, S.C.; validation, S.S.; formal analysis, H.K.; investigation, J.P.; data curation, J.K.; writing-original draft preparation, H.K.; writing-review and editing, I.J.; visualization, D.-S.B.; supervision, I.J.; project administration, S.C.; funding acquisition, S.C. All authors have read and agreed to the published version of the manuscript.

Funding: This research was supported by the National R\&D Program through the National Research Foundation of Korea (NRF) funded by the Ministry of Science and ICT (2020M3H4A3105945) and the Korea Institute for Advancement of Technology (KIAT) grant funded by the Korea Government (MOTIE) (P0012451, The Competency Development Program for Industry Specialist).

Institutional Review Board Statement: Not applicable.

Informed Consent Statement: Not applicable.

Data Availability Statement: The data and analysis in this study are available on request from the corresponding author.

Acknowledgments: This research was supported by the Basic Science Research Capacity Enhancement Project through a Korea Basic Science Institute (Core-facility for Converging Materials) grant funded by the Ministry of Education (2019R1A6C1010045).

Conflicts of Interest: The authors declare no conflict of interest.

\section{References}

1. Averbeck, S.; Spriestersbach, D.; Kerscher, E. Mechanism of fine granular area and white etching crack formation in AISI 52100 bearing steel. Theor. Appl. Fract. Mech. 2020, 108, 102664. [CrossRef]

2. Panda, A.; Sahoo, A.K.; Kumar, R.; Das, R.K. A review on machinability aspects for AISI 52100 bearing steel. Mater. Today Proc. 2020, 23, 617-621. [CrossRef]

3. Spille, J.; Wranik, J.; Barteldes, S.; Mayer, J.; Schwedt, A.; Zürcher, M.; Lutz, T.; Wang, L.; Holweger, W. A study on the initiation processes of white etching cracks (WECs) in AISI 52100 bearing steel. Wear 2021, 477, 203864. [CrossRef]

4. Pena, L.V.W.; Wang, L.; Mellor, B.G.; Huang, Y. White etching structues in annealed 52100 bearing steel arising from high-pressure torsion tests. Tribol. Int. 2021, 164, 107187. [CrossRef]

5. Jayakanth, J.J.; Chandrasekaran, M.; Pugazhenthi, R. Impulse excitation analysis of material defects in ball bearing. Mater. Today Proc. 2021, 39, 717-724. [CrossRef]

6. Gould, B.; Greco, A.; Stadler, K.; Xiao, X. An analysis of premature cracking associated with microstructural alterations in an AISI 52100 failed wind turbine bearing using X-ray tomography. Mater. Des. 2017, 117, 417-429. [CrossRef]

7. Ozturk, K.; Gecu, R.; Karaaslan, A. Microstructure, wear and corrosion characteristics of multiple-reinforced $\left(\mathrm{SiC}-\mathrm{B}_{4} \mathrm{C}-\mathrm{Al}_{2} \mathrm{O}_{3}\right) \mathrm{Al}$ matrix composites produced by liquid metal infiltration. Ceram. Int. 2021, 47, 18274-18285. [CrossRef]

8. Ghandvar, H.; Jabbar, M.A.; Koloor, S.S.R.; Petru, M.; Bahador, A.; Baker, T.A.A.; Kondoh, K. Role B ${ }_{4}$ C Addition on Microstructure, Mechanical, and Wear Characteristics of Al-20\%Mg 2 Si Hybrid Metal Matrix Composite. Appl. Sci. 2021, 11, 3047. [CrossRef]

9. Akhtar, F. Microstructure evolution and wear properties of in situ synthesized $\mathrm{TiB}_{2}$ and $\mathrm{TiC}$ reinforced steel matrix composites. J. Alloys Compd. 2008, 459, 491-497. [CrossRef]

10. Wang, Z.; Lin, T.; He, X.; Shao, H.; Tang, B.; Qu, X. Fabrication and properties of the TiC reinforced high-strength steel matrix composite. Int. J. Refract. Metals Hard Meter. 2016, 58, 14-21. [CrossRef]

11. Dunstan, M.K.; Paramore, J.D.; Fang, Z.Z. The effects of microstructure and porosity on the competing fatigue failure mechanisms in powder metallurgy Ti-6Al-4V. Int. J. Fatigue 2018, 116, 584-591. [CrossRef]

12. Fan, K.C.; Chen, S.H.; Chen, J.Y.; Liao, W.B. Development of auto defect classification system on porosity powder metallurgy products. NDT E Int. 2010, 43, 451-460. [CrossRef]

13. Lee, Y.H.; Kim, N.; Lee, S.B.; Kim, Y.; Cho, S.; Lee, S.K.; Jo, I. Microstructure and mechanical properties of lightweight TiC-steel composite prepared by liquid pressing infiltration process. Mater. Charact. 2020, 162, 110202. [CrossRef]

14. Hu, Y.; Cong, W. A review on laser deposition-additive manufacturing of ceramics and ceramic reinforced metal matrix composites. Ceram. Int. 2018, 44, 20599-20612. [CrossRef]

15. Li, N.; Huang, S.; Zhang, G.; Qin, R.; Liu, W.; Xiong, H.; Shi, G.; Blackburn, J. Progress in additive manufacturing on new materials: A review. Mater. Sci. Technol. 2019, 35, 242-269. [CrossRef] 
16. Gülsoy, H.Ö. Production of injection moulded 316L stainless steels reinforced with TiC(N) particles. Mater. Sci. Technol. 2008, 24, 1484-1491. [CrossRef]

17. Cho, S.; Lee, Y.H.; Ko, S.; Park, H.; Lee, D.; Shin, S.; Jo, I.; Kim, Y.; Lee, S.B.; Lee, S.K. Enhanced high-temperature compressive strength of $\mathrm{TiC}$ reinforced stainless steel matrix composites fabricated by liquid pressing infiltration process. J. Alloys Compd. 2020, 817, 152714. [CrossRef] 